\title{
PENGARUH MUTU LAYANAN SARANA DAN PRASARANA TERHADAP KEPUASAN SISWA
}

\author{
${ }^{1}$ Asril Sairi \& ${ }^{2}$ M. Safrizal \\ ${ }^{1}$ SMA Muhammadiyah 1 Palembang \\ ${ }^{2}$ SMA Negeri 1 Betung \\ e-mail: ${ }^{1}$ asrilsairi84@gmail.com ${ }^{2}$ msaprizal27@gmail.com
}

\begin{abstract}
Abstrak: Generally, this study aims to find out the true picture regarding the quality of infrastructure services to the satisfaction of students in SMA Muhammadiyah 1 Palembang. The method used in this research is descriptive method with quantitative approach. The technique of collecting data using questionnaires that were distributed to 275 students as the study sample. The result of the calculation using the general trend show that student satisfaction in the high category with an average score of 4.24 and quality of services in environmental infrastructure SMA Muhammadiyah 1 Palembang included in the high category with an average score of 3.53. The correlation analysis using Pearson Product Moment, the correlation coefficient between variables $X$ and $Y$ is equal to 0.786 which shows that the correlation between the two variables are at high-level relations. The results of the significance test that is $5.264>1,968692$, it means that the correlation coefficient between variables $X$ and $Y$ are significant with linear regression analysis equation $\hat{Y}=50,022+$ $0,493 X_{1}$, this means that any change in one unit variable $X$ will be followed by a change of variable $Y$ for 0,493. It is concluded that there is a positive and significant relationship of quality service infrastructures on students' satisfaction in SMA Muhammadiyah 1 Palembang.
\end{abstract}

Keyword: Quality Service; Infrastructures; Students' Satisfaction

\section{PENDAHULUAN}

Pembelajaran efektif adalah pembelajaran di mana siswa memperoleh keterampilan-keterampilan yang spesifk, pengetahuan dan sikap serta merupakan pembelajaran yang disenangi siswa (Aprilana dkk, 2017). Untuk mencapai pembelajaran efektif diperlukan pengelolaan sarana dan prasarana sekolah. Pengelolaan sarana dan prasarana sangat penting karena dengan adanya pengelolaan sarana dan prasarana lembaga pendidikan akan terpelihara dan jelas kegunaanya. Dalam pengelolaan pihak sekolah harus dapat bertanggung jawab terhadap sarana dan prasarana terutama kepala sekolah yang langsung menangani sarana dan prasarana tersebut. Dan pihak sekolahpun harus dapat memelihara dan memperhatikan sarana dan prasarana sekolah yang sudah ada. Maka dengan adanya sarana dan prasarana di sekolah siswa dapat belajar dengan maksimal dan seefesien mungkin.

Dalam Kamus Besar Bahasa Indonesia (2001: 999) secara umum pengertian sarana adalah segala sesuatu yang dapat dipakai sebagai alat dalam mencapai maksud dan tujuan; alat; media. Sedangkan menurut tim penyusun Dirjen 
Dikdasmen Depdikbud yang dikutip oleh Arikunto (1988: 103), bahwa sarana pendidikan adalah semua fasilitas yang diperlukan dalan proses belajar mengajar baik bergerak maupun tidak bergerak agar pencapaian tujuan dapat berjalan lancar dan teratur, efektif dan efisien. Menurut Sukirman, dkk (1999: 28), sarana pendidikan adalah suatu sarana penunjang bagi proses pembelajaran baik yang bergerak maupun yang tidak bergerak agar pencapaian tujuan pendidikan berjalan lancar, teratur, efektif, dan efisien, termasuk di dalamnya barang habis pakai maupun yang tidak habis pakai. Berdasarkan pendapat yang dikemukakan oleh ahli di atas dapat disimpulkan bahwa sarana pendidikan adalah semua fasilitas yang digunakan dalam proses pembelajaran baik yang bergerak maupun yang tidak bergerak agar dalam pencapaian tujuan pendidikan berjalan lancar, teratur, efektif dan efisien.

Pentingnya sarana dan prasarana untuk menunjang proses pendidikan, diatur oleh Undang-Undang Republik Indonesia No 20 tahun 2003 tentang sistem pendidikan Nasional "Setiap satuan pendidikan formal dan non formal menyediakan sarana dan prasarana yang memenuhi keperluan pendidikan sesuai dengan pertumbuhan dan perkembangan potensi fisik, kecerdasan intelektual, sosial, emosional, dan kewajiban peserta didik"
Hal tersebut dipertegas dalam Peraturan Pemerintah No: 19 Tahun 2005 pada bab VII pasal 42 ayat 2 mencantumkan bahwa: Setiap satuan pendidikan wajib memiliki prasarana yang meliputi lahan ruang kelas, ruang pimpinan satuan pendidikan, ruang pendidik, ruang tata usaha, ruang perpustakaan, ruang laboratorium, ruang bengkel kerja tempat berolahraga, tempat beribadah, tempat bermain, tempat berkreasi dan ruang/tempat lain yang diperlukan untuk menunjang proses pembelajaran yang teratur dan berkelanjutan.

Sarana pendidikan adalah peralatan dan perlengkapan yang secara langsung dipergunakan dan menunjang proses pendidikan khususnya prose belajarmengajar, seperti gedung, ruang kelas, meja kursi, serta alat-alat dan media pengajaran (Susilaningrum, 2011). Terkadang kepuasan siswa terhadap fasilitas sekolah tidak dapat menjadi suatu penunjang untuk kelarasan jalannya proses belajar mengajar itu sendiri yang pada akhirnya berpengaruh kepada standar kelulusan, kondisi siswa, prestasi, akademik, prestasi non-akademik, kepribadian, manajemen, kepemimpinan, kurikulum, guru, kepala sekolah, tenaga pendukung, organisasi dan administrasi, sarana prasarana, pembiayaan, regulasi sekolah, hubungan masyarakat dan kultur sekolah. 
Proses Belajar Mengajar (PBM) atau Kegiatan Belajar Mengajar (KBM) akan semakin sukses bila ditunjang dengan sarana dan prasarana sekolah yang memadai, sehingga pemerintah pun selalu berupaya untuk terus-menerus melengkapi sarana dan prasarana sekolah bagi seluruh jenang tingkatan pendidikan, sehingga kekayaan fisik negara yang berupa sarana dan prasarana sekolah sangat besar menurut (Ari, 1996:114). Menurut Mulyasa (2004:49) sarana dan prasarana sebagai salah satu komponen penunjang proses pembelajaran merupakan alat yang sering digunakan guru untuk merealisasikan tujuan pembelajaran tersebut.

Sarana pendidikan berfungsi langsung (kehadirannya sangat menentukan) terhadap Proses Belajar Mengajar (PBM), seperti alat pelajaran, alat peraga, alat praktek dan media pendidikan, sedangkan prasarana pendidikan berfungsi tidak langsung (kehadirannya tidak sangat menentukan). Termasuk dalam prasarana pendidikan adalah tanah, halaman, pagar, tanaman, gedung/bangunan sekolah, jaringan jalan, air, listrik, telepon, serta prabot/mobiler (Gunawan, 1996:115). Pada umumnya di lingkungan semua lembaga pendidikan diperlukan sarana prasarana untuk memadai jalannya proses belajar mengajar, serta menunjang proses belajar mengajar. Dengan demikian maka fungsi sarana pada dasarnya sebagai alat bantu dalam proses aktivitas belajar mengajar.

Fungsi dan tujuan dari sarana prasarana pendidikan adalah sebagai berikut: Selain memberi makna penting bagi terciptanya dan terpeliharanya kondisi sekolah yang optimal, administrasi sarana dan prasarana sekolah berfungsi sebagai: 1) Memberi dan melengkapi fasilitas untuk segala kebutuhan yang di perlukan dalam proses belajar mengajar. 2) Memelihara agar tugas-tugas murid yang di berikan oleh guru dapat terlaksana dengan lancar dan optimal.

Mengingat sekolah itu merupakan subsistem pendidikan nasional maka tujuan dari administrasi sarana dan prasarana itu bersumber dari tujuan pendidikan nasional itu sendiri. sedangkan subsistem administrasi sarana dan prasarana dalam sekolah bertujuan untuk menunjang tercapainya tujuan pendidikan sekolah tersebut, baik tujuan khusus maupun tujuan secara umum. Adapun tujuan dari administrasi sarana dan prasarana itu adalah: 1) Mewujudkan situasi dan kondisi sekolah yang baik sebagai lingkungan belajar maupun sebagai kelompok belajar ,yang memungkinkan peserta didik untuk mengembangkan kemampuan semaksimal mungkin. 2) Menghilangkan berbagai hambatan yang dapat menghalangi terwujudnya interaksi dalam pembelajaran. 3) Menyediakan dan mengatur fasilitas serta 
perabot belajar yang mendukung dan memungkinkan siswa belajar sesuai dengan lingkungan sosial, emosional, dan intelektual siswa dalam proses pembelajaran. 4) Membina dan membimbing siswa sesuai dengan latar belakang sosial, ekonomi, budaya serta sifatsifat individunya.

Mengembangkan sarana prasarna sekolah termasuk membantu Pendidikan karakter. Menurut Suprapto (2014) large population is the most important for the progress and setbacks of a nation depends on human factors. The problems of politic, economic, social can also be completed by human resources. However, to solve the problems and deal with the high civilization competition become more advanced, Indonesia needs revitalization and strengthening strong character of human resources. One aspect that can be done to prepare for the strong human character is through education (Kristiawan, 2015). Menurut Suyatno (2010) Education is the only key that can achieve strong human resources (Kristiawan, 2015).

Menurut Suprapto (2014) Pendidikan karakter tidak sekadar mengajarkan mana yang benar dan mana yang salah, tetapi juga menanamkan kebiasaan (habituation) tentang hal mana yang baik (Wulandari dan Kristiawan, 2017). Menurut Ahmad dkk (2017) pembelajaran karakter adalah membentuk budaya sekolah, yaitu perilaku, tradisi, kebiasaan keseharian, dan simbolsimbol yang dipraktikkan oleh semua warga sekolah, dan masyarakat sekitar sekolah. Dengan begitu, peserta didik menjadi paham (kognitif) tentang mana yang baik dan salah, mampu merasakan (afektif) nilai yang baik (loving the good/moral feeling), dan perilaku yang baik (moral action), dan biasa melakukan (psikomotor) (Kristiawan, 2016). Pendidikan karakter adalah sebuah sistem yang menanamkan nilai-nilai karakter pada peserta didik, yang mengandung komponen pengetahuan, kesadaran individu, tekad, serta adanya kemauan dan tindakan untuk melaksanakan nlai-nilai, baik terhadap Tuhan Yang Maha Esa, diri sendiri, sesama manusia, lingkungan, maupun bangsa, sehingga akan terwujud insan kamil (Renata dkk, 2017).

Penelitian terkait pentingnya sarana dan prasarana antara lain dilakukan oleh Darmawan (2014) yang hasil penelitiannya menyimpulkan bahwa Standar sarana prasarana Sekolah merupakan bagian dari kebijakan untuk memperbaiki dan meningkatkan layanan dasar dan kualitas dari penyelenggaraan pendidikan. Penelitian lain dilakukan oleh Sari (2015) kesimpulanya menyatakan bahwa standarisasi sarana dan prasarana pendidikan berpengaruh terhadap hasil belajar siswa. 
Pemilihan SMA Muhammadiyah 1 Palembang menjadi tempat penelitian didasarkan pada beberapa hal, yaitu; 1) dekat dengan tempat tinggal peneliti, 2) SMA Muhammadiyah 1 Palembang merupakan salah satu sekolah swasta Islam terbesar di Palembang yang menarik untuk diteliti.

\section{METODE PENELITIAN}

Metode yang digunakan dalam penelitian ini adalah metode deskriptif dengan pendekatan kuantitatif. Menurut Sugiyono (2011:14), metode penelitian kuantitatif diartikan sebagai metode penelitian yang berlandaskan pada filsafat positivisme, digunakan untuk meneliti pada populasi atau sampel tertentu, teknik pengambilan sampel dilakukan secara random dengan tujuan untuk menguji hipotesis yang telah ditetapkan. Sample dalam penelitian ini adalah siswa SMA Muhammadiyah 1 Palembang yang berjumlah 275 orang. Instrumen yang digunakan yaitu angket, sebelum instrumen disebar kepada responden, dilakukan uji coba terlebih dahulu terhadap instrumen yang telah disusun yaitu dengan melakukan uji validitas dan uji reliabilitas.

Teknik pengumpulan data yang digunakan dalam penelitian ini adalah dengan menggunakan angket tertutup. Adapun langkah-langkah analisis data dalam penelitian ini dimulai dengan seleksi data, menghintung kecenderungan umum skor responden dari masing-masing variabel.

\section{HASIL DAN PEMBAHASAN}

Hasil penelitian didapatkan dari pengolahan instrumen angket yang telah diisi oleh responden. Pengolahan hasil penelitian dilakukan dengan bantuan program Microsoft Excel 2013 dan SPSS for windows 20.0 untuk mengetahui seberapa besar pengaruh antara variabel X (Mutu Layanan Sarana dan Prasarana) terhadap variabel Y (Kepuasan Siswa). Selanjutnya, penyebaran angket disebar sebanyak 275 buah dengan jumlah item pertanyaan untuk variabel $\mathrm{X}$ sebanyak 11 buah dan untuk variabel Y sebanyak 11 buah. Berdasarkan hasil perhitungan, diketahui bahwa nilai rata-rata dari keseluruhan item variabel $\mathrm{Y}$ (Kepuasan siswa) sebesar 4,24. Dengan demikian Kepuasan Siswa di SMA Muhammadiyah 1 Palembang termasuk dalam kategori baik. Berdasarkan hasil perhitungan, dapat diketahui bahwa nilai rata-rata keseluruhan variabel $\mathrm{X}$ (Mutu Layanan Sarana dan Prasarana) yaitu sebesar 3,53. Dengan demikian mutu layanan sarana dan prasarana termasuk dalam kategori baik, artinya bahwa mutu layanan sarana dan prasarana SMA Muhammadiyah 1 Palembang telah dirasakan baik oleh siswa. 
Selanjutnya akan dilakukan analisis koefisien korelasi dengan menggunakan teknik Pearson Product Moment. Kemudian dilakukan pengujian hipotesis, pengujian hipotesis dimaksudkan agar hipotesis yang telah dirumuskan dalam penelitian ini ditolak atau diterima. Berdasarakan hasil perhitungan korelasi antara variabel $\mathrm{X}$ dan variabel Y menunjukan nilai sebesar 0,786, menunjukan bahwa variabel $\mathrm{X}$ dan variabel Y berada pada klasifikasi tinggi yaitu berada diantara 0,60-0,786, dengan demikian interpretasi terhadap koefisien korelasi adalah terdapat hubungan yang tinggi antara mutu layanan sarana dan prasrana terhadap kepuasan siswa.

\section{Tabel Uji Signifikan}

\section{Coefficients $^{\mathrm{a}}$}

\begin{tabular}{llllll}
\hline & \multicolumn{2}{l}{$\begin{array}{l}\text { Unstandardized } \\
\text { Coefficients }\end{array}$} & \multicolumn{2}{l}{$\begin{array}{l}\text { Standardized } \\
\text { Coefficients }\end{array}$} & \\
\cline { 2 - 4 } Model & B & Std. Error & Beta & t & Sig. \\
\hline 1 (Constant) & 50.022 & 6.636 & & 7.538 & .000 \\
Media Sosial & .493 & .094 & .304 & 5.264 & .000 \\
\hline
\end{tabular}

a. Dependent Variable:

Motivasi Belajar

Pengujian signifikansi dimaksudkan untuk mengukur tingkat signifikansi antara variabel X dan variabel Y. Berdasarkan hasil perhitungan diperoleh harga adalah 5.264 sedangkan dengan $\alpha=0,05$ uji satu pihak dan $\mathrm{dk}=\mathrm{n}-2=275-2=273$, diperoleh $=$ 1,968692. Dengan demikian, karena 5.264 >
1,968692, maka artinya bahwa keofisien korelasi antara variabel $\mathrm{X}$ dan $\mathrm{Y}$ adalah signifikan. Maka kesimpulan dari pengujian hipotesis ini adalah "Terdapat pengaruh yang positif dan signifikan antara mutu layanan sarana dan prasarana terhadap kepuasan siswa di SMA Muhammadiyah 1 Palembang".

Untuk mengetahui besarnya pengaruh antara variabel $\mathrm{X}$ dengan variabel Y maka dilakukan perhitungan dengan uji koefisien determinasi. Dari hasil perhitungan koefisien determinasi menunjukkan bahwa variabel Y (Kepuasan siswa) dipengaruhi sebesar $61,77 \%$ oleh variabel X (Mutu Layanan Sarana dan Prasarana) sedangkan sisanya $38,23 \%$ dipengaruhi oleh variabel lain.

Selanjutnya melakukan analisis regresi. Berdasarkan hasil koesisien, diketahui bahwa koefisien a sebesar 50,022 sedangkan harga koefisien b adalah 0,493. Sehingga diperoleh persamaan linier yaitu:

$$
\hat{Y}=50,022+0,493 X_{1},
$$

ini berarti bahwa setiap ada perubahan pada satu unit variabel $\mathrm{X}$ maka akan diikuti oleh perubahan variabel $\mathrm{Y}$ sebesar 0,493. Pembahasan dalam penelitian ini akan membahas mengenai hasil penelitian berdasarkan hasil temuan di lapangan. Mutu layanan merupakan suatu tingkatan ukuran 
baik atau buruknya suatu layanan yang diberikan pihak sekolah kepada para siswa yang diharapkan sesuai dengan keinginan para siswa khususnya di bidang sarana dan prasarana. Berdasarkan hasil perhitungan, diketahui bahwa rata-rata skor variabel $\mathrm{x}$ sebesar 3,53 dengan kategori baik. Hal ini menunjukkan bahwa mutu layanan sarana dan prasarana yang dilakukan oleh staf bidang sarana dan prasarana SMA Muhammadiyah 1 Palembang dapat dirasakan sudah baik.

Berdasarakan perhitungan dari variabel $\mathrm{Y}$, diketahui gambaran skor ratarata dari kepuasan siswa di SMA Muhammadiyah 1 Palembang sebesar 4,24 dan hasil perhitungan koefisien korelasi sebesar 0,786. Dari hasil tersebut menunjukkan bahwa kepuasan siswa di SMA Muhammadiyah 1 Palembang dalam kategori tinggi. Adapun hal-hal yang menunjukkan tingkat kepuasan siswa tersebut yaitu: kinerja staf, aktivitas siswa, bangunan sekolah, dan komunikasi.

Dari hasil penelitian dan pembahasan maka diperoleh kesimpulan hasil penelitian ini mengenai Mutu Layanan Sarana dan Prasarana Terhadap Kepuasan siswa, dimana Mutu Layanan Sarana dan Prasarana memiliki pengaruh terhadap Kepuasan siswa. Sehingga jawaban dari hipotesis penelitian ini adalah Ho diterima, yaitu terdapat hubungan yang positif dan signifikan antara variabel X dan Variabel Y.

\section{KESIMPULAN}

Adapun kesimpulan dari hasil penelitian adalah sebagai berikut: 1) Berdasarkan hasil pengolahan data tingkat kepuasan siswa yang dirasakan oleh siswa di SMA Muhammadiyah 1 Palembang termasuk dalam kategori baik. 2) Berdasarkan hasil pengolahan data penelitian diketahui bahwa mutu layanan sarana dan prasarana di SMA Muhammadiyah 1 Palembang termasuk dalam kategori baik dan tingkat hubungan yang tinggi. 3) Berdasarkan hasil pengolahan data diperoleh derajat hubungan atau kontribusi variabel mutu layanan sarana dan prasarana terhadap kepuasan siswa sebesar $62,57 \%$. Hal ini menjelaskan bahwa mutu layanan sarana dan prasarana berpengaruh sebesar $62,57 \%$ terhadap kepuasan siswa di SMA Muhammadiyah 1 Palembang, sedangkan $37,43 \%$ nya dipengaruhi oleh faktor lain. 4) Berdasarkan uji signifikansi antara mutu layanan sarana dan prasarana dengan kepuasan siswa menunjukkan terdapat hubungan yang signifikan. Artinya bahwa koefisien korelasi antara variabel $\mathrm{X}$ dan $\mathrm{Y}$ adalah signifikan. Maka jawaban dari hipotesis penelitian ini yaitu terdapat hubungan yang positif dan signifikan antara variabel X (mutu layanan 
sarana dan prasarana) dan Variabel $\mathrm{Y}$ (kepuasan siswa).

\section{DAFTAR PUSTAKA}

Ahmad, S., Kristiawan, M., Tobari, T., \& Suhono, S. (2017). Desain Pembelajaran SMA Plus Negeri 2 Banyuasin III Berbasis Karakter Di Era Masyarakat Ekonomi ASEAN. Iqra (Educational Journal), 2(2), 403432.

Aprilana, E. R., Kristiawan, M., \& Hafulyon, H. (2017). Kepemimpinan Kepala Madrasah Dalam Mewujudkan Pembelajaran Efektif di Madrasah Ibtidaiyah Rahmah El Yunusiyyah Diniyyah Puteri Padang Panjang. Elementary, 4(1).

Ari, H Gunawan. 1996. Administrasi Sekolah, Administrasi Pendidikan Mikro. Jakarta: Rineka Cipta

Depdiknas. 2001. Kamus Besar Bahasa Indonesia. Jakarta: Balai Pustaka

Gunawan, H. Ary. 1996. Administrasi Sekolah (Administrasi Pendidikan Mikro). Jakarta: PT Rineka Cipta Cet. 1

Kristiawan, M. (2015). A Model of Educational Character in High School Al-Istiqamah Simpang Empat, West Pasaman, West Sumatera. Research Journal of Education, 1(2), 15-20.

Kristiawan, M. (2016). Telaah Revolusi Mental Dan Pendidikan Karakter Dalam Pembentukkan Sumber Daya Manusia Indonesia Yang Pandai dan Berakhlak Mulia. Ta'dib, 18(1), 13-25.

Mulyasa, E. 2004. Manajemen Berbasis Sekolah. Bandung: Remaja Rosdakarya
Renata, R., Kristiawan, M., \& Pratami, F. A. R. (2017, December). Perbincangan Pendidikan Karakter. In Prosiding Seminar Nasional Program Pascasarjana.

Sugiyono. 2011. Metode Penelitian Pendidikan. Bandung. Afabeta

Sukirman, Hartati. 1999. Administrasi Supervisi Pendidikan. Yogyakarta: UNY

Susilaningrum, S. 2011. "Analisis permasalahan siswa dalam memahami pelajaran IPA biologi kelas VII kompetensi dasar mendeskripsikan keragaman pada sistem organisasi kehidupan mulai dari tingkat sel sampai organisme di SMP AtThohiriyyah Semarang tahun ajaran 2010/2011". IAIN Walisongo

Wulandari, Y., \& Kristiawan, M. (2017). Strategi Sekolah dalam Penguatan Pendidikan Karakter Bagi Siswa dengan Memaksimalkan Peran Orang Tua.JMKSP (Jurnal Manajemen, Kepemimpinan, dan Supervisi Pendidikan), 2(2) 